\title{
Unusual Correlation between SKPFM and Corrosion of Nickel Aluminum Bronzes
}

\author{
M. Iannuzzi, ${ }^{\text {a, }, \text { d,z }}$ K. L. Vasanth, ${ }^{\text {b }}$ and G. S. Frankel ${ }^{\mathrm{c}, * *}$ \\ ${ }^{a}$ Norwegian University of Science and Technology, Corrosion and Surface Protection, Department of Mechanical and \\ Industrial Engineering - MTP, Faculty of Engineering Science and Technology—IVT, Trondheim N7491, Norway \\ ${ }^{b}$ Naval Surface Warfare Center Carderock Diviision, Code 613, West Bethesda, Maryland 20817-5700, USA \\ ${ }^{c}$ Fontana Corrosion Center, Materials Science, and Engineering Department, The Ohio State University, Columbus, \\ Ohio 43210, USA
}

\begin{abstract}
Scanning Kelvin probe force microscopy was used to investigate the influence of microstructure on the corrosion behavior of nickel aluminum bronzes in ammoniacal and $\mathrm{NaCl}$ solutions as well as under potential control in $\mathrm{Na}_{2} \mathrm{SO}_{4}$. The results showed an inverse correlation between the measured Volta potential difference and the observed corrosion behavior. In other words, the phase with initially higher Volta potential was preferentially attacked whereas those with the lowest Volta potential difference values remained intact. This behavior suggests that Volta potential difference maps in air cannot be universally correlated with practical nobility or reactivity in solution, as proposed by other investigators. The implications of these findings are discussed.

(C) The Author(s) 2017. Published by ECS. This is an open access article distributed under the terms of the Creative Commons Attribution 4.0 License (CC BY, http://creativecommons.org/licenses/by/4.0/), which permits unrestricted reuse of the work in any medium, provided the original work is properly cited. [DOI: 10.1149/2.0391709jes] All rights reserved.

(cc) BY
\end{abstract}

Manuscript submitted April 27, 2017; revised manuscript received June 16, 2017. Published June 28, 2017.

Nickel aluminum bronzes.-Nickel aluminum bronzes (NABs) are $\mathrm{Cu}$-based alloys with a typical nominal composition of $10 \mathrm{wt} \%$ $\mathrm{Al}, 5 \mathrm{wt} \% \mathrm{Ni}$, and $5 \mathrm{wt} \% \mathrm{Fe}^{1}{ }^{1}$ NABs combine high strength, usually equal to or above that of medium carbon steels, i.e., up to 450 $\mathrm{MPa}(60 \mathrm{ksi})$, and toughness with adequate corrosion resistance to marine environments. ${ }^{2}$ Other attractive properties of NABs include their low magnetic permeability, excellent wear, galling, cavitation, and antifouling resistance, as well as being non-sparking and having a $10 \%$ lower density than steels. ${ }^{3}$ In the maritime and oil and gas industries, NABs find numerous applications including valves and pumps, ship propellers, and heat exchangers. ${ }^{3,4}$

The physical metallurgy of NABs is extremely complex and strongly influenced by thermo-mechanical processing history. ${ }^{5}$ The thermodynamics and kinetics of phase transformations in NABs have been studied in detail by Culpan and Rose, ${ }^{6}$ Brezina, ${ }^{7}$ Hasan and coworkers, ${ }^{1,8-10}$ and Wu et al., ${ }^{11}$ among others. Although NABs solidify as a single body-centered cubic (bcc) $\beta$-phase, at room temperature they consist of a Cu-rich face-centered cubic (fcc) $\alpha$-phase and several IMCs that some authors refer to collectively as $\kappa$-phase. ${ }^{1} \mathrm{Ni}, \mathrm{Fe}$, and $\mathrm{Mn}$ combine with aluminum to form the various $\kappa$-phases, extending the apparent stability range of the $\alpha$ field and retarding the formation of the deleterious $\gamma_{2}$-phase from the decomposition of $\beta .{ }^{6}$ In this regard, $\beta$ decomposes to $\alpha$ and $\gamma_{2}$ during annealing or slow cooling below $565^{\circ} \mathrm{C}$, which has plagued binary $\alpha / \beta$ aluminum bronzes with more than $9.4 \% \mathrm{Al}^{7}$

Under equilibrium cooling conditions, there are four types of IMCs in NABs, which are summarized in Table I. ${ }^{1,5,6,8}$ Cast NABs with a Fe content above 4.4-5.0 wt\% often present large, i.e., between 20 and $50 \mu \mathrm{m}$, dendritic- or rosette-shaped particles named $\kappa_{\mathrm{I}}$, which precipitate in the center of the $\alpha$ grains and do not exhibit a single crystal structure. ${ }^{8}$ In wrought and cast NABs, $\kappa_{\text {II }}$ precipitates, typically between 5 to $10 \mu \mathrm{m}$, form by decomposition of the high temperature $\beta$-phase. The $\kappa_{\mathrm{II}}$-phase is based on $\mathrm{Fe}_{3} \mathrm{Al}$ with $\mathrm{Ni}, \mathrm{Cu}$, and $\mathrm{Mn}$ substituting for iron. It often forms alongside the lamellar $\kappa_{\text {III }}$ eutectoid decomposition product. ${ }^{1,5} \kappa_{\text {III }}$ is based on $\mathrm{Ni}-\mathrm{Al}$, with $\mathrm{Fe}, \mathrm{Cu}$, and $\mathrm{Mn}$ substituting for Ni. Likewise, equiaxed $\kappa_{\mathrm{IV}}$-phase precipitates form when the solubility of iron in the $\alpha$-phase is exceeded. $\kappa_{\mathrm{IV}}$ is based on $\mathrm{Fe}_{3} \mathrm{Al}$ and finely dispersed within $\alpha$ grains. ${ }^{1,12}$ Depending on composition and thermomechanical processing details, retained $\beta$ or $\beta^{\prime}$ with a martensitic structure can be present and it is seen as dark regions

\footnotetext{
*Electrochemical Society Member.

**Electrochemical Society Fellow.

${ }^{\mathrm{d}}$ Present address: Curtin Corrosion Engineering Industry Center, School of Chemical and Petroleum Engineering, Curtin University, Perth, WA 6855, Australia.

${ }^{z}$ E-mail: mariano.iannuzzi@curtin.edu.au
}

in optical micrographs. ${ }^{5}$ Likewise, complex martensitic, bainitic, and Widmanstätten phases form during fast cooling, and can be used to increase strength and toughness. ${ }^{5}$

The pitting and crevice corrosion resistance of NABs in marine environments has been studied extensively and various comprehensive overviews are available in the literature. ${ }^{2,13-18}$ The influence of NAB microstructure on localized corrosion is addressed in detail in the Discussion section below. Briefly, at a fixed chloride concentration, researchers have shown that the corrosion morphology is strongly influence by $\mathrm{pH}^{2,15,17}$ The $\alpha$ phase was found to suffer preferential dissolution in slightly acidic to alkaline environments, whereas the various $\kappa$ phases exhibited selective attack at low $\mathrm{pH}$ values. In contrast, limited work has been done to determine the effect of microstructure on stress corrosion cracking (SCC) susceptibility. In this regard, Fonlupt and coworkers showed that NABs are susceptible to SCC in seawater both at the open circuit potential (OCP) and under a net cathodic polarization. ${ }^{19}$ The SCC resistance was highly influenced by microstructure, with galvanic interactions between phases playing a predominant role. Similarly, Vasanth and Hays found that NABs with different compositions and microstructures exhibited varying degrees of SCC resistance. ${ }^{20}$ Vasanth and Hays also found that the presence of ammonia was especially detrimental, in agreement with the well-documented performance of $\mathrm{Cu}$-based alloys in ammoniacal solutions..$^{21,22}$ Despite this evidence, there seems to be no consensus on a plausible SCC mechanism.

Scanning Kelvin Probe force microscopy.-The use of the scanning Kelvin probe force microscopy (SKPFM) technique was introduced into corrosion research by Schmutz, Frankel, and coworkers between 1998 and 2001..$^{23-25}$ In their original work, the authors found a linear relationship between the OCP of several pure metal samples during exposure to deionzed (DI) water, $0.5 \mathrm{M} \mathrm{NaCl}$, or $0.1 \mathrm{M} \mathrm{Na}_{2} \mathrm{SO}_{4}$ and the Volta potential difference, $\Delta \psi$, measured on those samples in air following removal from those solutions. Reactive metals such as $\mathrm{Mg}$ and $\mathrm{Al}$, as well as nobler metals like $\mathrm{Cu}, \mathrm{Ni}, \mathrm{Au}$, and $\mathrm{Pt}$, were investigated. The linear relationship resembled the linear correlation between the Volta potential measured by the traditional Scanning Kelvin Probe (SKP) technique above a sample covered with a thin layer of electrolyte and the OCP determined by a reference electrode in the electrolyte layer reported by Stratmann and collaborators. ${ }^{26}$ More recently, Cook et al. compared SKPFM and SKP on $99.9 \%$ pure $\mathrm{Zn}, \mathrm{Fe}, \mathrm{Cu}, \mathrm{Ni}$ and Ag surfaces. ${ }^{27}$ The authors reported a good correlation between $\Delta \psi$ values obtained in air by SKPFM and those of SKP in the presence of a thin aqueous humidity layer. Cook and coworkers concluded that it 
Table I. Possible phases present in as-cast and wrought NAB., ${ }^{1,6,18}$

Composition (at\%)

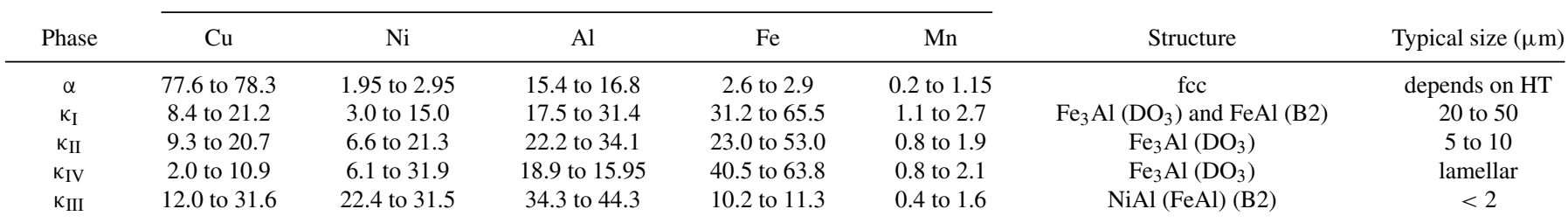

is possible to calibrate Volta potential values obtained by SKPFM directly against OCP, provided that SKPFM measurements are performed under well-controlled conditions (e.g., relative humidity, temperature, surface finish, tip-surface distance, and tip properties).

When applied to heterogeneous aluminum alloys, such as AA2024T3, Schmutz, Frankel, and coworkers found that Volta potential difference maps provided an indication of the practical nobility of each particle relative to the matrix. ${ }^{23,24}$ It is important to note that, depending on the type of AFM, Volta potential difference maps have to be inverted to reflect the correct polarity. The authors found that $\mathrm{Al}-\mathrm{Cu}-(\mathrm{Fe}$, $\mathrm{Mn}$ ) intermetallic compounds (IMCs) gave a higher $\Delta \psi$ value than the Al-rich matrix (i.e., the IMC appeared bright on the Volta potential difference maps), even after exposure or $\mathrm{Ar}^{+}$sputter-etching. ${ }^{24,28}$ $\mathrm{Al}_{2} \mathrm{CuMg}$ (S-phase) particles also exhibited what the authors called noble Volta potentials in the as-polished condition, which contrasted with their documented selective anodic behavior. ${ }^{29}$ The authors concluded that the high $\Delta \psi$ value was a consequence of a $\mathrm{Cu}$-rich air formed film that was degraded in solution prior to dissolution of the S-phase particles. The Volta potential decreased after AFM scratching, $\mathrm{Ar}^{+}$sputter-etching, and immersion in $\mathrm{NaCl}$. The Volta potential of the $\mathrm{Al}_{2} \mathrm{CuMg}$ IMC subsequently became equal to or lower than that of the matrix. ${ }^{24,28}$ The statistical analysis of SKPFM measurements on more than $300 \mathrm{~S}$-phase particles by Lacroix et al. supports these observations, ${ }^{30}$ although the investigators did not invert or refer $\Delta \psi$ values to nickel.

By combining SKPFM and in situ AFM scratching, Leblanc and Frankel demonstrated that $\mathrm{Al}-\mathrm{Cu}-(\mathrm{Fe}, \mathrm{Mn}) \mathrm{IMC}$ were preferential cathodic sites, with local dissolution observed at the boundary between the IMC and the matrix. ${ }^{28}$ The authors also found that some S-phase particles corroded without the presence on the exposed surface of Al$\mathrm{Cu}-(\mathrm{Fe}, \mathrm{Mn}) \mathrm{IMCs}$, leaving a high-potential $\mathrm{Cu}-$ rich remnant. When combined with local electrochemical measurements or electrochemical studies on synthetic IMCs, SKPFM results explained the observed corrosion morphology as well as the anodic or cathodic behavior of IMCs in aluminum alloys. ${ }^{31-34}$

The mechanism of aluminum alloy corrosion inhibition by hexavalent chromate compounds was also studied using a combination of AFM, SKPFM, and scanning electron microscopy (SEM) -energy dispersive X-ray spectroscopy (EDS) ${ }^{28,35}$ The combination of techniques allowed the authors to determine the $\mathrm{Cr}^{6+}$ corrosion inhibition mechanism. Leblanc and Frankel, for instance, established that dichromate ions formed a strong protective film on both $\mathrm{Al}_{2} \mathrm{CuMg}$ and $\mathrm{Al}-\mathrm{Cu}-(\mathrm{Fe}$, $\mathrm{Mn}$ ) IMCs, preventing cathodic and anodic reactions. ${ }^{28}$

In their comprehensive overview of the SKP and SKPFM techniques, Rohwerder and Turcu investigated the possible correlation between OCP evolution during immersion and the Volta potential measured upon emersion. ${ }^{36}$ The authors compared the behavior of freely-exposed pure $\mathrm{Fe}$ and $\mathrm{Nb}$ as a function of $\mathrm{pH}$ in a chloride-free $1 \mathrm{M} \mathrm{Na}_{2} \mathrm{SO}_{4}$ electrolyte, and potentiostatically polarized $\mathrm{Nb}$ samples exposed to a fixed $\mathrm{pH}(\mathrm{pH} 2)$. Additionally, $\mathrm{Fe}$ and $\mathrm{Nb}$ samples were galvanically coupled and immersed in $1 \mathrm{M} \mathrm{Na}_{2} \mathrm{SO}_{4}$ solutions of $\mathrm{pH}$ 2.0, 4.0, and 12.0. Iron and niobium were chosen since they have opposite corrosion behaviors as a function of $\mathrm{pH}$. In other words, whereas $\mathrm{Fe}$ is active in acids, ${ }^{37} \mathrm{Nb}$ suffers active dissolution in alkaline environments. ${ }^{38}$ The authors used SKP instead of SKPFM to map Volta potentials given that the goal of the investigation was to explore a possible universal relationship.
Rohwerder and Turcu concluded that no universal link exists between differences measured by SKP and corrosion behavior. ${ }^{36}$ The results indicated that Volta potentials on freely exposed $\mathrm{Fe}$ and $\mathrm{Nb}$ and potentiostatically polarized $\mathrm{Nb}$ measured by $\mathrm{SKP}$ upon emersion would have led to erroneous conclusions about the active-to-passive transition of both metals. Moreover, Volta potentials measurements on $\mathrm{Fe}$ and $\mathrm{Nb}$ after galvanic coupling at different $\mathrm{pH}$ values suggested that $\mathrm{Nb}$ was the net anode of the pair when, in fact, the opposite was true. The researchers further concluded that potential difference maps measured by SKPFM would not give the correct contrast, as they are typically more prone to artifacts than SKP. Lastly, the authors suggested that, unless the corrosion behavior of an alloy is well characterized and the contrast of Volta potential difference maps well understood, SKPFM results could be misleading.

Muster and Hughes studied the applications and limitations of SKPFM for the analysis of the corrosion behavior of aluminum alloys. ${ }^{39}$ The authors investigated Volta potential difference contrasts on AA2024-T3, pure aluminum with electrodeposited $\mathrm{Cu}$ and $\mathrm{Fe}$ islands, as well as aluminum alloys from the 7xxx and 5xxx series. Additionally, the effect of the thickening of surface oxides was investigated on both AA2024 and pure $\mathrm{Cu}$. Muster and Hughes concluded that the ability of SKPFM to provide information about the corrosion behavior of an alloy was limited to features less than $2 \mu \mathrm{m}$ in depth. In all cases, since accurate mapping of surface topography is a prerequisite, failure to trace the topography led to erroneous Volta potential measurements. Furthermore, results were strongly influenced by scan rate, with higher rates leading to tip disengagement or poor tracing. The Volta potential difference monotonically increased (i.e., moved in the positive direction) with increased oxide thickness and was strongly influenced by oxide composition. Likewise, the findings on electrodeposited surfaces suggested that the Volta potential difference maps in air were dominated by the element with the highest work function.

Recent SKPFM investigations on NAB will be addressed in detail below. In short, Nakhaie et al. ${ }^{40}$ and Song and coworkers ${ }^{41}$ have used a combination of SKPFM and ex situ immersion testing to evaluate $\mathrm{NAB}$ corrosion. Both researchers found selective dissolution of the various IMCs when NAB was exposed to acid chloride environments. Immersion in neutral $\mathrm{NaCl}$ led to corrosion at the IMC-matrix interface. The investigators did not, however, studied the evolution of Volta potential maps as a function of immersion time.

Others have used SKPFM to study corrosion and corrosion inhibition mechanism of aluminum alloys, ${ }^{28,42,43}$ magnesium alloys, ${ }^{4-46}$ stainless steels, ${ }^{47-51} \mathrm{AlSiMg}$ alloys produced by additive manufacturing, ${ }^{52}$ nickel-based alloys, ${ }^{53}$ low alloy steels, ${ }^{54,55}$ and filiform corrosion mechanisms, ${ }^{56-58}$ to name a few examples. It has now become a common practice to refer to low $\Delta \psi$ values (i.e., dark areas in Volta potential difference maps) as anodic regions and high $\Delta \psi$ (i.e., bright areas) as cathodic.

Despite the limitations described by Rohwerder and Turcu, ${ }^{36}$ many alloy systems exhibit a morphology after exposure in corrosive conditions that is predicted by the relative practical nobility determined by SKPFM done in air in the as-polished condition. For example, particles that had a high or noble Volta potential difference exhibited higher pitting potentials $\left(\mathrm{E}_{\mathrm{Pit}}\right)$ than the matrix, acted as local cathodes, or both. ${ }^{23,24,45,47,48}$ In all cases, noble IMCs or phases were enriched in elements that have a relatively high work function such as $\mathrm{Cu}, \mathrm{Cr}$, $\mathrm{Mo}, \mathrm{Ni}$, and $\mathrm{W}^{59}$ The implications of the partitioning of noble metal 
Table II. UNS C63200 nominal composition.

\begin{tabular}{cccccccc} 
Designation & $\begin{array}{c}\mathrm{Cu} \\
(\mathrm{wt} \%)\end{array}$ & $\begin{array}{c}\mathrm{Ni} \\
(\mathrm{wt} \%)\end{array}$ & $\begin{array}{c}\mathrm{Al} \\
(\mathrm{wt} \%)\end{array}$ & $\begin{array}{c}\mathrm{Fe} \\
(\mathrm{wt} \%)\end{array}$ & $\begin{array}{c}\mathrm{Mn} \\
(\mathrm{wt} \%)\end{array}$ & $\begin{array}{c}\mathrm{Si} \\
(\mathrm{wt} \%)\end{array}$ & $\begin{array}{c}\mathrm{Pb} \\
(\mathrm{wt} \%)\end{array}$ \\
\hline UNS C63200 & bal. & $4.0-4.8$ & $8.7-9.5$ & $3.5-4.3$ & $1.2-2.0$ & 0.1 & 0.02 \\
(ASTM B171) & & & & & & max & $\max$
\end{tabular}

elements to the various constituents of a heterogeneous alloy will be discussed in more detail below.

The objective of this work is to explore the use of SKPFM as a tool to investigate the early stages of NAB corrosion in simulated marine environments. A better understating of the role played by the difference in electrochemical behavior between the various phases present in NABs could support the study of both SCC and localized corrosion phenomena.

\section{Experimental}

Materials.-Rolled UNS C63200 plates, produced according to the ASTM B171 specification, ${ }^{60}$ were used in this investigation. Table II shows the nominal composition of UNS C63200. Two different metallurgical conditions were evaluated: as received (AR) and heat treated (HT). Samples in the AR condition were rolled and creepformed at $565^{\circ} \mathrm{C}$. HT samples were annealed for $1 \mathrm{~h}$ at $927^{\circ} \mathrm{C}$, followed by furnace cooling to room temperature.

Test samples were sectioned using a precision, low-speed diamond saw. The dimensions of the test specimens were approximately $1 \mathrm{~cm} \times$ $1 \mathrm{~cm} \times 2 \mathrm{~mm}$, adapted to fit inside the small AFM sample holder head. Coupons were ground and polished with 3-, 1-, and 1/4- $\mu \mathrm{m}$ diamond paste. Ethyl alcohol ( $<0.2 \%$ water) was used as a lubricant during all the surface preparation stages to minimize possible corrosion damage during grinding and polishing. Before analysis, samples were cleaned in an ultrasonic bath, rinsed with ethyl alcohol, and dried with $99.5 \%$ argon gas.

Solution preparation.-Three different electrolytes were investigated. A chloride-containing ammoniacal solution was prepared by mixing $25 \%$ ammonia liquor in a prepared $\mathrm{NaCl}$ electrolyte to give 10 vol $\% \mathrm{NH}_{3}(\mathrm{aq})+0.5 \mathrm{M} \mathrm{NaCl}$. The unadjusted $\mathrm{pH}$ of the ammoniacal solution was $\mathrm{pH}=12.2$. NAB samples were also exposed to $0.5 \mathrm{M}$ $\mathrm{NaCl}$ with a nearly neutral $\mathrm{pH}(\mathrm{pH}=6.0)$. Lastly, anodic and cathodic polarizations were conducted in a chloride-free $0.1 \mathrm{M} \mathrm{Na}_{2} \mathrm{SO}_{4}$ electrolyte with an as-prepared $\mathrm{pH}$ of 5.3. Reagent-grade $\mathrm{NaCl}$ and $\mathrm{Na}_{2} \mathrm{SO}_{4}$ chemicals were used. All solutions were prepared with $18.2 \mathrm{M} \Omega \cdot \mathrm{cm}$ deionized water.

Scanning Kelvin probe force microscopy.-Mapping of topography and Volta potential difference was performed in air before and after exposure, using a Bruker (Veeco) Nanoscope III AFM. Commercially available Pt-Ir coated Si cantilevers with a resonance frequency of $40 \mathrm{KHz}$ to $70 \mathrm{KHz}$ were employed in all cases. Topography maps were conducted using the tapping mode of operation. Details of the SKPFM procedure can be found elsewhere. ${ }^{23,24}$ In short, potential measurements are taken during a second scan in the so-called lift mode. Measurements involve applying an ac voltage to a tip (typically $\pm 1 \mathrm{~V}$ ), which stimulates oscillations of the cantilever in the presence of an electric field. The oscillations are, then, nulled by adding a dc voltage that balances the field. The AFM model used in this work required the inversion of the output signal to reflect the expected polarity of the potential measurements. ${ }^{23}$ Volta potential difference measurements were performed at a tip-sample distance of 100 $\mathrm{nm}$. Images were recorded over an area of 80 by $80 \mu \mathrm{m}$ at a scan rate of 0.5 lines/s, and the scanned area contained 512 by 512 points. Under this set of conditions, recording each frame took approximately 17 minutes. Absolute Volta potentials are reported with respect to the Volta potential measured in air on a pure (i.e., 99.95\%) Ni sample, which served as a calibration standard. The nickel sample used as a reference was polished to 1200 grit and then immersed for $30 \mathrm{~min}$ in water prior to each calibration to create a reproducible surface. ${ }^{56}$ Absolute VP measurements were taken on several locations over the scanned surface and the range are presented.

Whereas both AR and HT microstructures were characterized in air, only the corrosion evolution of HT NAB specimens was investigated. HT NAB samples were freely exposed to $0.5 \mathrm{NaCl}+10 \mathrm{vol} \%$ $\mathrm{NH}_{3}$ (aq.) or $0.5 \mathrm{M} \mathrm{NaCl}$. Samples were withdrawn from solution after various periods of immersion. Coupons exposed to the ammoniacal solution were analyzed at $15,30,45$, and $105 \mathrm{~min}$. Samples exposed to $0.5 \mathrm{M} \mathrm{NaCl}$ only were analyzed at 1,2 , and $24 \mathrm{~h}$. At each interval, the coupons were removed from the glass cell, rinsed with DI-water and dried using argon. Both topography and Volta potential difference maps were recorded ex situ to obtain the time evolution of the corrosion attack. Test coupons were returned to the glass cell after completing the SKPFM analysis and the process was repeated until the end of the exposure. The duration of an ex situ SKPFM analysis step took approximately 20 to 25 minutes.

The effect of anodic and cathodic polarization on the resulting Volta potential difference profile was also examined. In this case, two identical working electrodes were electrically coupled, immersed 0.1 $\mathrm{M} \mathrm{Na}_{2} \mathrm{SO}_{4}$ with a $\mathrm{pH}$ of 5.3, and polarized. Samples were polarized, after a 10 minutes OCP exposure, to either $70 \mathrm{mV}$ above $\mathrm{E}_{\mathrm{Corr}}$, resulting in a constant current of $\mathrm{I}=+200 \mu \mathrm{A}$, or $200 \mathrm{mV}$ below $\mathrm{E}_{\mathrm{Corr}}$, leading to a stable current of $\mathrm{I}=-58 \mu \mathrm{A}$. After $30 \mathrm{~min}$, one of the coupons was removed from the electrolyte under controlled applied potential, while the other electrode was kept immersed under applied potential. Coupons were then rinsed with DI-water and dried with argon. SKPFM was conducted on the sample emersed from solution immediately after the rinsing and drying steps.

SEM-EDS.-Samples were characterized by SEM-EDS before and after exposure. After SEM analysis, and before SKPFM, the samples were lightly re-polished using $1 / 4-\mu \mathrm{m}$ diamond paste. Secondary and backscattered electron images were obtained using an acceleration voltage of $12 \mathrm{keV}$ to $20 \mathrm{keV}$.

Reproducibility.-Experiments were repeated at least in duplicate, and two different areas were analyzed per sample. However, because each selected region is virtually unique in distribution, shape, and composition of phases, no two experiments can be considered exact replicates.

\section{Results}

Microstructure characterization.-The goal of the heat-treatment procedure is to reduce the strength of the AR samples and thereby improve the SCC resistance. ${ }^{20}$ As seen in Table III, the AR plate had a yield strength (YS) almost double that of the HT plate, at the expense of a much-reduced elongation to failure. The tensile strength (TS) and YS of the HT plate material approached those reported for cast $\mathrm{NAB},{ }^{20}$ but with notably improved ductility.

Figure 1 compares the microstructure of the AR and HT conditions as revealed by SEM. Samples in the AR conditions contained $\kappa_{I I}, \kappa_{I I I}$, and $\kappa_{\text {IV }}$ IMCs. The iron-containing $\kappa_{\text {II }}$ particles were approximately 2 to $3 \mu \mathrm{m}$ in diameter and were present both inside the $\alpha$ matrix or

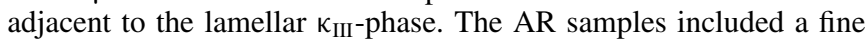
dispersion of $\kappa_{\mathrm{IV}}$ IMC within $\alpha$ grains. The annealing heat-treatment

Table III. Mechanical properties of the tested samples. Cast NAB added as reference.

\begin{tabular}{ccccc} 
Condition & $\begin{array}{c}\text { Tensile strength } \\
\text { MPa (ksi) }\end{array}$ & $\begin{array}{c}\text { Yield Strength, } \\
\sigma_{0.2} \mathrm{MPa}(\mathrm{ksi})\end{array}$ & $\begin{array}{c}\text { Elongation } \\
(\%)\end{array}$ & $\begin{array}{c}\text { Hardness } \\
(\mathrm{HRB})\end{array}$ \\
\hline As Received & $731(106)$ & $455(66)$ & 13 & 203 \\
Heat Treated & $620(90)$ & $262(38)$ & 25 & 155 \\
Cast NAB & $586(85)$ & $241(35)$ & 15 & $84-89$
\end{tabular}




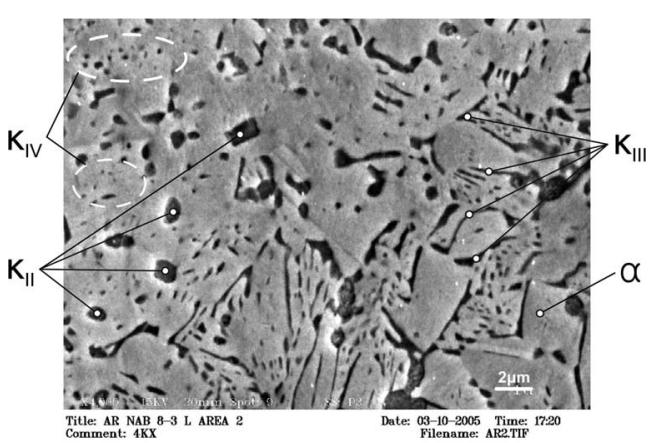

(a)

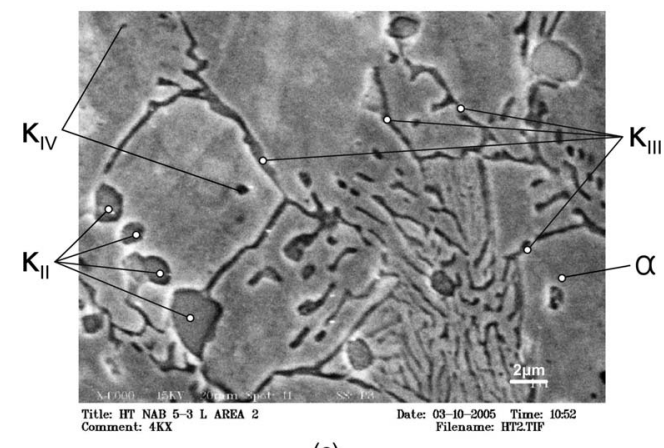

(c)

Figure 1. As-polished UNS C63200 NAB SEM image before exposure: (a) as received and (b) heat treated.

resulted in coarsening of the $\alpha$ grains, coarsening of the $\kappa_{\text {II }}$ particles to about 4 to $6 \mu \mathrm{m}$ and partial dissolution of the small $\kappa_{\mathrm{IV}}$ precipitates. Small $\kappa_{\text {III }}$ lamella in the AR condition became more continuous after heat-treatment.

\begin{tabular}{|c|c|c|c|c|c|}
\hline \multirow[b]{2}{*}{ Phase } & \multicolumn{5}{|c|}{ Composition (at\%) } \\
\hline & $\mathrm{Cu}$ & $\mathrm{Ni}$ & $\mathrm{Al}$ & $\mathrm{Fe}$ & $\mathrm{Mn}$ \\
\hline$\alpha$ & 81.0 & 3.04 & 11.5 & 2.06 & 2.18 \\
\hline$\kappa_{\text {III }}$ & 60.72 & 10.0 & 22.47 & 4.39 & 2.21 \\
\hline$\kappa_{\text {II }}$ & 4.56 & 5.58 & 16.24 & 61.0 & 5.58 \\
\hline
\end{tabular}

Table IV compares the chemical composition of the $\alpha$-phase and both $\kappa_{\text {II }}$ and $\kappa_{\text {III }}$ precipitates as obtained by EDS. Although EDS analysis on small precipitates is inaccurate, the results showed that $\kappa_{\mathrm{II}}$ was markedly enriched in $\mathrm{Fe}$ and $\mathrm{Al}$ and depleted in $\mathrm{Cu}$, whereas $\kappa_{\text {III }}$ had a higher $\mathrm{Ni}$ and $\mathrm{Al}$ content than the matrix. All phases contained $\mathrm{Mn}$, but $\kappa_{\text {II }}$ precipitates appeared to have an Mn content double that of $\alpha$. Due to their small dimensions, no reliable measurements could be obtained on the finely dispersed $\kappa_{\text {IV }}$ particles. The literature suggests they should be similar in structure to $\kappa_{\text {II }}$ but with a somewhat higher Fe content (Table I). ${ }^{12}$

Figure 2 shows topography and Volta potential difference maps of both AR and HT samples in the as-polished condition. As seen in Figure 2, some IMCs, primarily the $\kappa_{\text {II }}$ and $\kappa_{I V}$ particles, were slightly receded from the matrix by about 30 to $70 \mathrm{~nm}$ due nonuniform removal or dissolution during polishing. Nevertheless, the differences in the complex microstructure seen in SEM analysis were not evident from topography maps alone. Volta potential difference maps, in contrast, clearly revealed the distribution, shape, and size of the various $\kappa$ phases, most of which were not distinguishable in the topography plots.

The mean absolute Volta potential difference of the $\alpha$-phase (measured only on the HT condition) calibrated to pure nickel was -620 $\mathrm{mV}_{\mathrm{Ni}}$. Interestingly, in both the AR and HT conditions, all IMCs had a Volta potential difference that was lower than that of the $\alpha$-matrix.
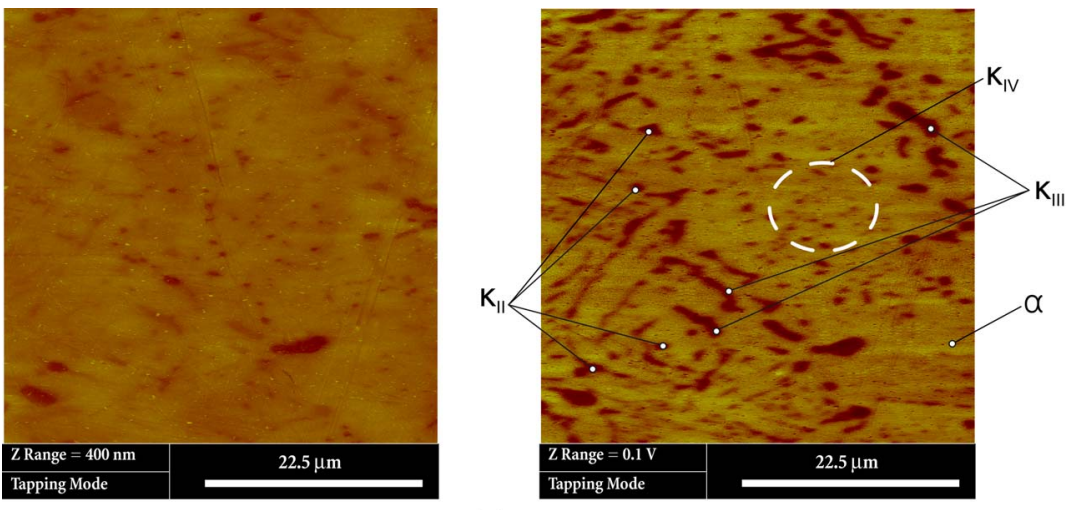

(a)

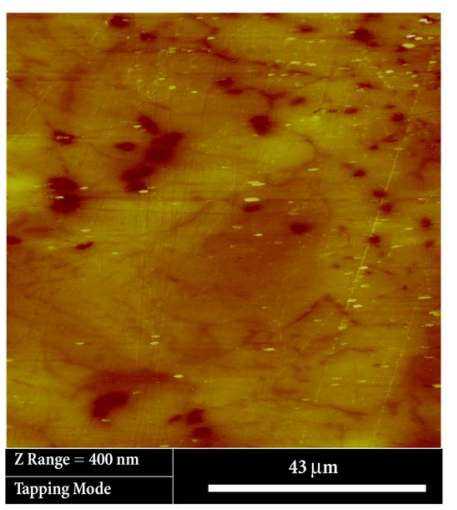

Figure 2. Topography (left) and Volta potential difference (right) maps of: (a) as received and (b) heat treated UNS C63200. Samples polished to $0.25 \mu \mathrm{m}$ diamond suspension, unetched. The labels indicate the type of IMC. 
Table V. Summary of local Volta potential values and the range, i.e., the difference between the maximum and the minimum values.

\begin{tabular}{|c|c|c|c|c|c|}
\hline Phase & Condition & Exposure & $\begin{array}{l}\text { Exposure } \\
\text { time (min) }\end{array}$ & $\begin{array}{r}\text { Average } \Delta \psi \\
\text { (mV vs. Ni) }\end{array}$ & $\begin{array}{c}\text { Range } \\
\Delta \psi(\mathrm{mV})\end{array}$ \\
\hline$\alpha$ & HT & As Polished & N/A & -620 & 10 \\
\hline$\kappa_{\mathrm{II}}$ & HT & As Polished & N/A & -564 & 10 \\
\hline$\kappa_{\text {III }}$ & HT & As Polished & N/A & -605 & 3 \\
\hline$\alpha$ & HT & Ammonia & 45 & -580 & 70 \\
\hline$\alpha$ & HT & Ammonia & 105 & -575 & 120 \\
\hline$\kappa_{\text {II }}$ & HT & Ammonia & 45 & -544 & 14 \\
\hline$\kappa_{\text {II }}$ & HT & Ammonia & 105 & -534 & 168 \\
\hline$\kappa_{\text {III }}$ & HT & Ammonia & 45 & -497 & 19 \\
\hline$\kappa_{\text {III }}$ & HT & Ammonia & 105 & -562 & 13 \\
\hline$\alpha$ & HT & Neutral $\mathrm{NaCl}$ & 1440 & -715 & 35 \\
\hline$\alpha$ & HT & Anodic $\mathrm{Na}_{2} \mathrm{SO}_{4}$ & 30 & -700 & 5 \\
\hline$\alpha$ & HT & Cathodic $\mathrm{Na}_{2} \mathrm{SO}_{4}$ & 30 & -625 & 10 \\
\hline
\end{tabular}

The $\kappa_{\text {II }}$ and lamellar $\kappa_{\text {III }}$ particles exhibited Volta potential differences that were on average about $56 \mathrm{mV}$ and $13-16 \mathrm{mV}$ lower than the matrix, respectively. Table $\mathrm{V}$ summarizes the average Volta potential differences and the range, i.e., the difference between the maximum and the minimum values. For comparison, the absolute Volta potential of the aluminum alloy AA2024-T3 matrix varies between -800 and $-750 \mathrm{mV}_{\mathrm{Ni}}$ while that of the Fe-containing IMCs is between -500 and $-450 \mathrm{mV}_{\mathrm{Ni}}$, i.e. roughly $300 \mathrm{mV}$ higher than the matrix. ${ }^{25}$ Nonetheless, these maps suggest that the $\kappa$ phases are slightly more active than the matrix phase and should preferentially dissolve upon exposure in corrosive solutions.

OCP exposure.-Ammoniacal solution.-Figure 3 illustrates the evolution of the topography and Volta potential difference of another HT sample as a function of exposure time to $0.5 \mathrm{M} \mathrm{NaCl}+10$ vol\% $\mathrm{NH}_{3(\mathrm{aq})}$. Even though they had lower Volta potential differences, the $\kappa$ phase IMCs showed no signs of corrosion while the $\mathrm{Cu}$-rich $\alpha$ grains suffered selective dissolution, Figure $3 \mathrm{c}$. This is in clear contrast to the well-documented behavior of, e.g., aluminum alloys. After 45 minutes of immersion, the IMCs were no longer recessed and instead protruded from the surface by $50-96 \mathrm{~nm}$. The Volta potential difference map exhibited a similar contrast to that observed in the aspolished condition, Figure 3d. All $\kappa$-phases retained a Volta potential lower than that of the matrix. The absolute Volta potential of the $\alpha$-matrix increased to $-580 \mathrm{mV}_{\mathrm{Ni}}$ after 45 minutes. Dissolution of the $\alpha$-phase continued during subsequent immersion cycles. After 105 minutes, IMCs protruded by roughly $100 \mathrm{~nm}$ from the surface and signs of corrosion products or surface roughening were observed over the $\alpha$ grains, Figure 3e. After 105 minutes, the Volta potential difference map displayed no clear contrast while the absolute $\Delta \psi$ value of the matrix increased to $-480 \mathrm{mV}_{\mathrm{Ni}}$, Figure $3 \mathrm{f}$ and Table $\mathrm{V}$. As shown in Table $\mathrm{V}$, the absolute Volta potential of both $\kappa_{\mathrm{II}}$ and $\kappa_{\text {III }}$ particles also decreased as a function of exposure time. Likewise, there was a significant dispersion in Volta potential values measured on IMCs after 105 min of exposure. This uncertainty was likely associated with the blurring of the Volta potential map observed after the long exposure.

SEM conducted short after the last SKPFM map confirmed the dissolution of the $\mathrm{Cu}$-rich matrix. As shown in Figure $4 \mathrm{a}, \kappa_{\mathrm{II}}$ particles and $\kappa_{\text {III }}$ lamella remained free of attack, protruding from the surface as suggested by topography plots. The corrosion attack did not concentrate at the interface between the $\kappa$-phases and the matrix but extended over the $\alpha$-grains, Figure $4 \mathrm{~b}$. The EDS mapping presented in Figure 5 and quantitative EDS analysis suggested that $\kappa$-phases suffered no de-alloying during exposure to the ammoniacal electrolyte as the composition of the many IMC remained qualitatively identical to that before immersion. The $\mathrm{Fe}, \mathrm{Al}$, and $\mathrm{Ni}$ maps shown in Figure 5 illustrate the partitioning of alloying elements to the different $\kappa$-phases.

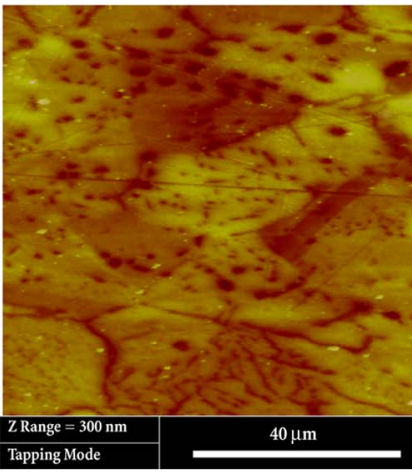

(a)

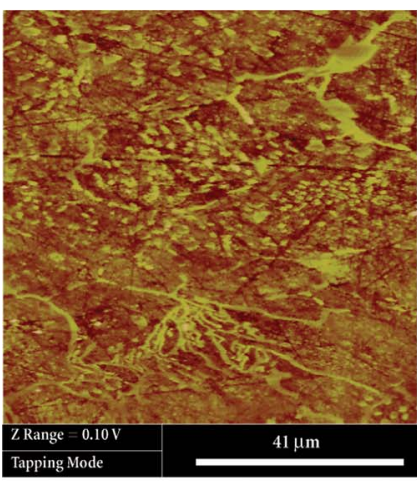

(c)

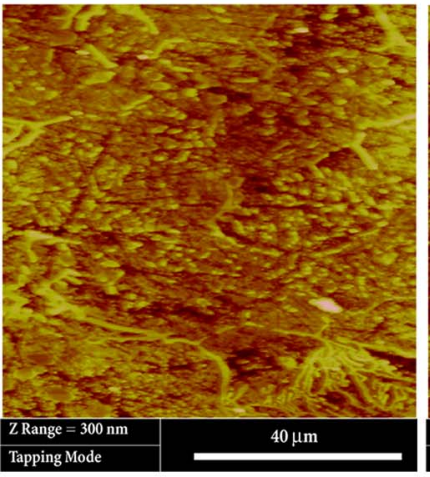

(e)

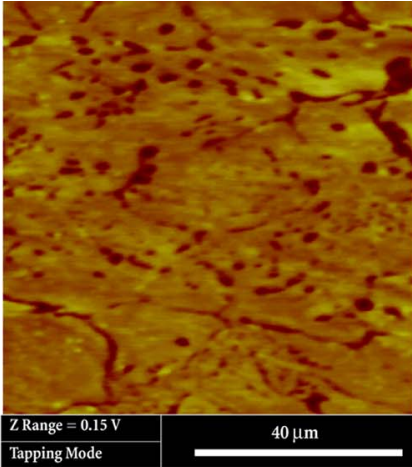

(b)

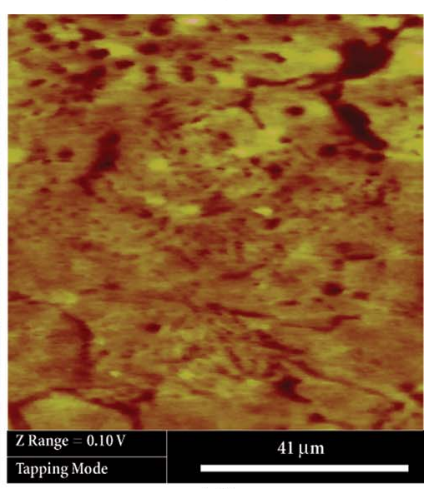

(d)

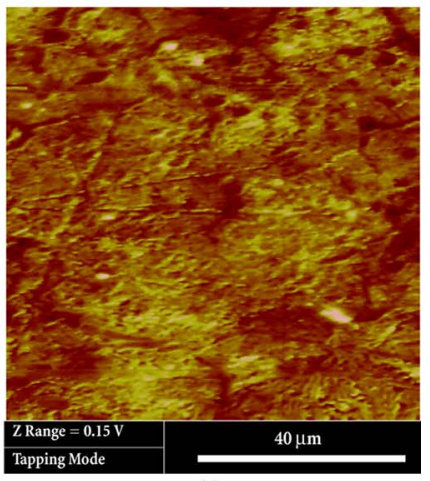

(f)
Figure 3. Topography (left) and Volta potential difference (right) evolution of as polished HT UNS C63200: (a) and (b) before exposure, (c) and (d) after 45 minutes, and (e) and (f) after 105 minutes of exposure to $0.5 \mathrm{M} \mathrm{NaCl}+10$ vol\% ammonia $(\mathrm{pH}=12.2)$.

Nearly neutral $\mathrm{NaCl}$ solution.-Figure 6 summarizes topography and Volta potential difference evolution as a function of immersion time of another HT sample in $0.5 \mathrm{M} \mathrm{NaCl}$ with $\mathrm{pH}$ 6.0. As indicated by the longer time intervals, the corrosion attack was much slower than in the ammoniacal solution. No noticeable attack was seen after $1 \mathrm{~h}$ of exposure. The Volta potential difference map retained the same contrast after 60 minutes with all $\kappa$-phases showing a lower Volta potential than the matrix. The absolute $\Delta \psi$ value of the matrix was $-600 \mathrm{mV}_{\mathrm{Ni}}$ in the as-polished condition and remained unchanged after the first hour of exposure. Because of the slow corrosion kinetics, samples were immersed for a total of $24 \mathrm{~h}$. Deposits and signs of surface roughening were seen after one day of immersion, but no visible corrosion of the matrix or the IMCs was detected in topography maps. After $24 \mathrm{~h}$, the contrast between the IMCs and the matrix disappeared, but areas of high and low Volta potential regions were still evident across the surface. Although some $\kappa_{\text {II }}$ particles retained their low Volta potential, the regions of high and low potential could 


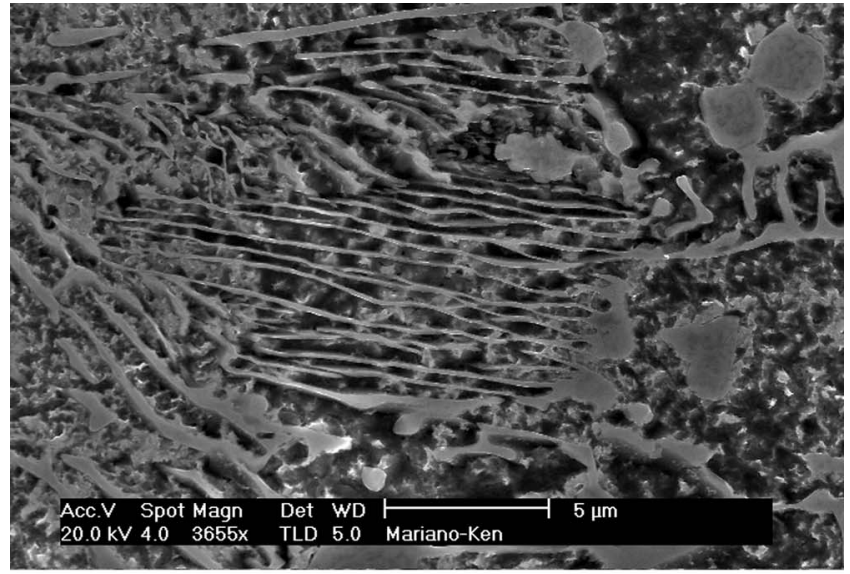

(a)

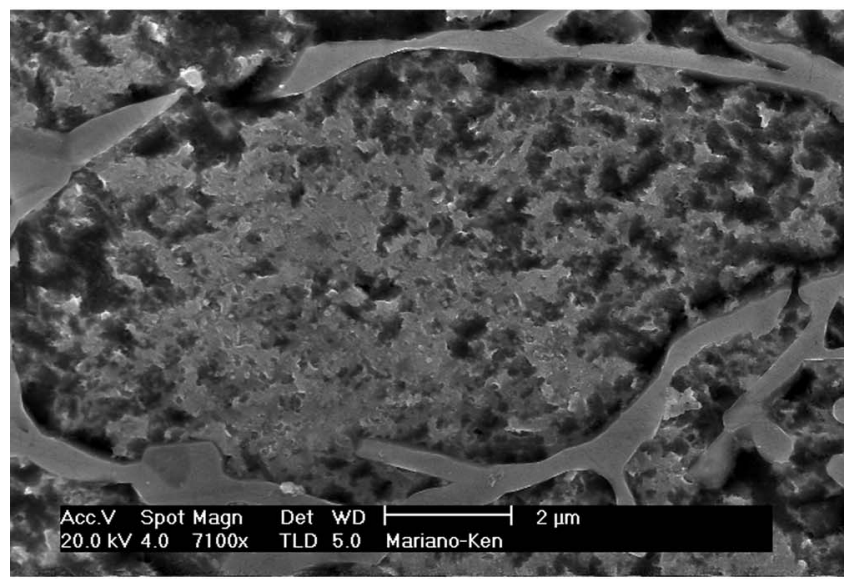

(b)

Figure 4. SEM of HT UNS C63200 after 105 minutes of exposure to $0.5 \mathrm{M}$ $\mathrm{NaCl}+10$ vol\% ammonia ( $\mathrm{pH}=12.2)$ : (a) overall appearance and (b) higher magnification illustrating the selective dissolution of the $\alpha$-phase. The many $\kappa$-phase particles did not show signs of corrosion.

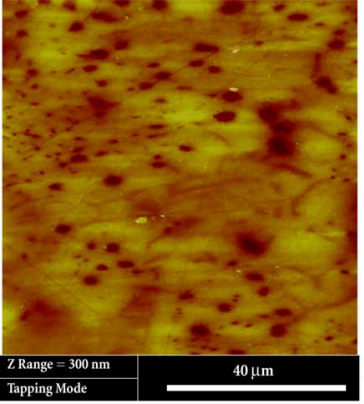

(a)

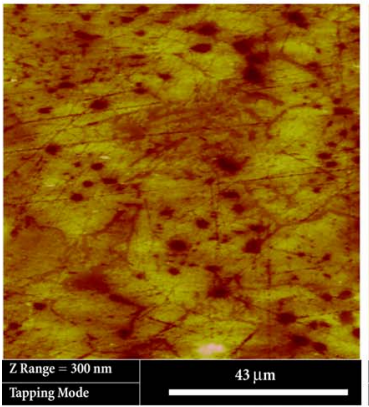

(c)

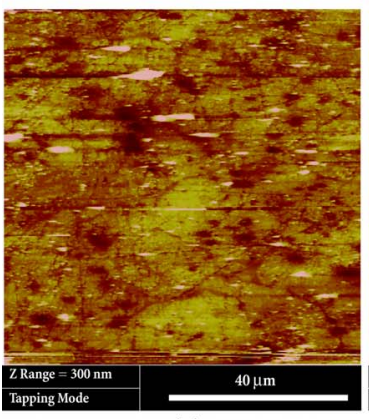

(e)

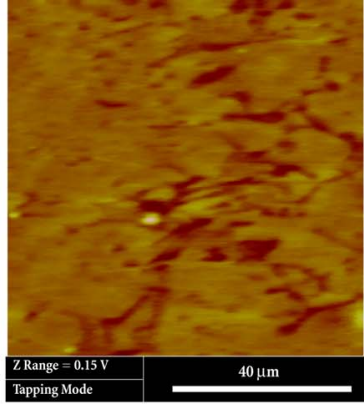

(b)

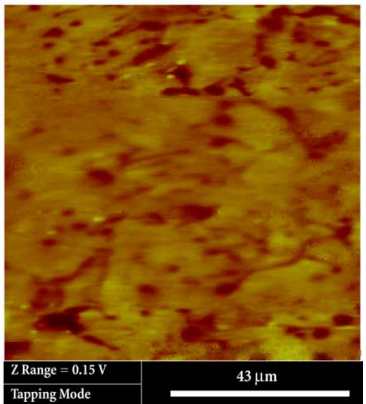

(d)

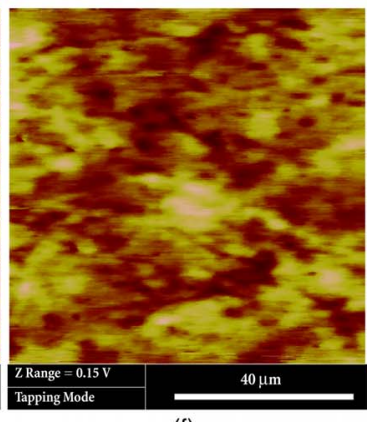

(f)
Figure 6. Topography (left) Volta potential difference (right) evolution of as polished UNS C63200: (a) and (b) before exposure, (c) and (d) after 60 minutes, and (e) and (f) after 24 hours of exposure to $0.5 \mathrm{M} \mathrm{NaCl}$ ( $\mathrm{pH}=6.0$, unadjusted).

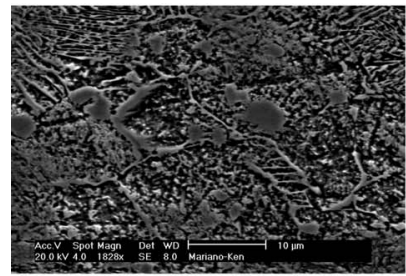

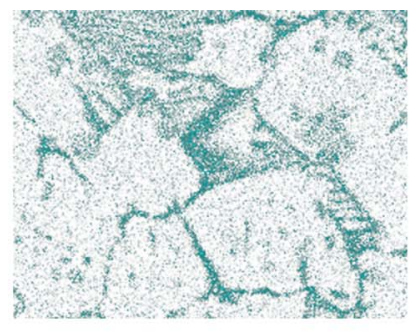

$\mathrm{Ni}$

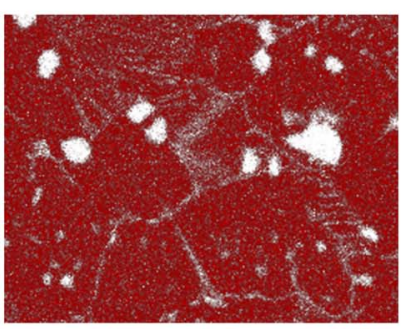

$\mathrm{Cu}$

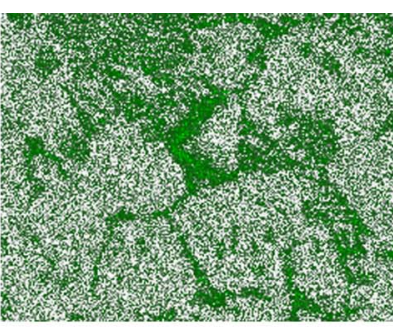

Al

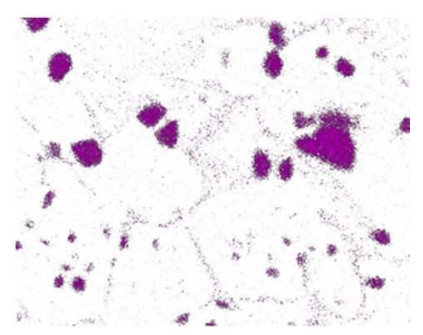

$\mathrm{Fe}$

Figure 5. SEM-EDS elemental maps of HT UNS C63200 after 105 minutes of exposure to $0.5 \mathrm{M} \mathrm{NaCl}+10$ vol\% ammonia $(\mathrm{pH}=12.2)$, elements as indicated. 


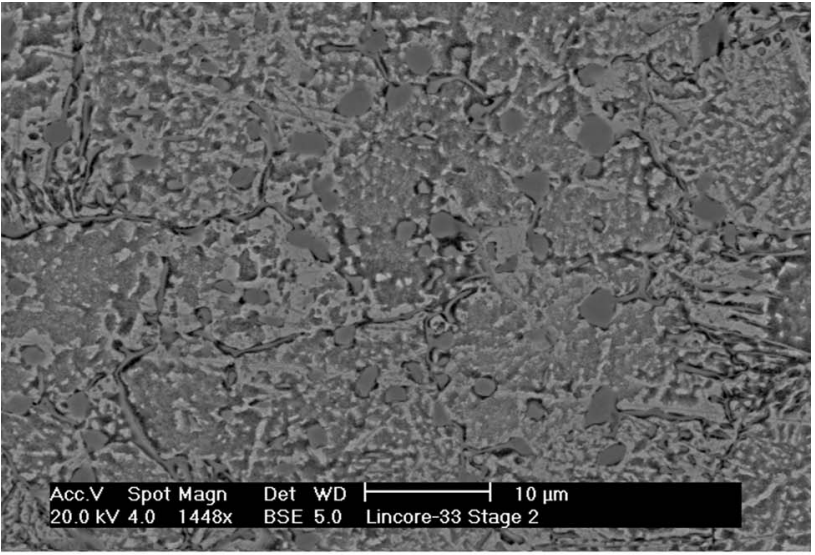

(a)

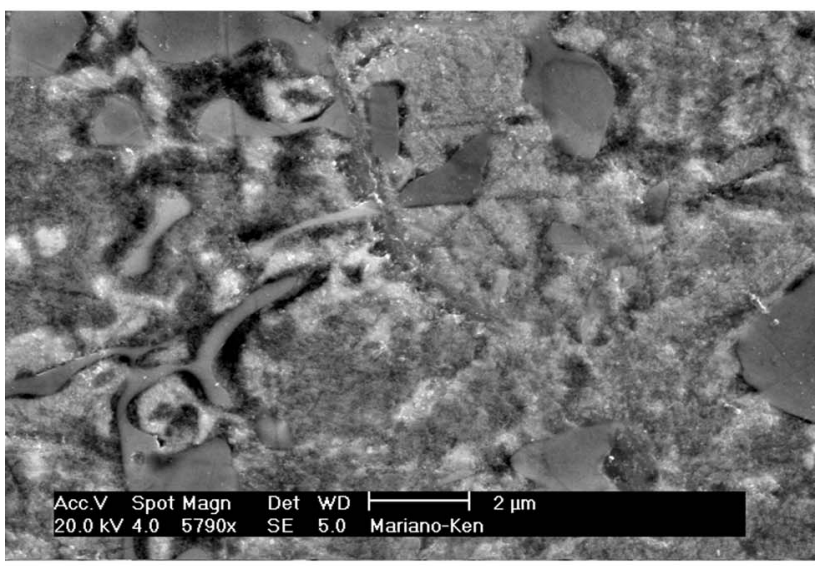

(b)

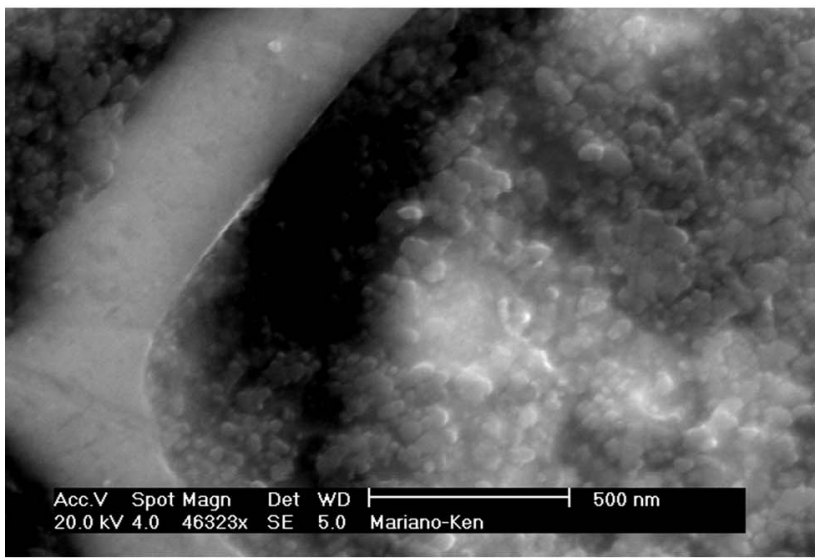

(c)

Figure 7. SEM of UNS C63200 after 105 minutes of exposure to $0.5 \mathrm{M} \mathrm{NaC}$ $(\mathrm{pH}=6.0$, unadjusted): (a) overall appearance, (b) and (c) higher magnification illustrating preferential attack at the $\alpha-\kappa$ interphase and the appearance of selective dissolution of the $\alpha$-phase. The various $\kappa$-phase particles did not show signs of corrosion. EDS analysis revealed the presence of a chloride-rich corrosion product over the corroded $\alpha$ grains.

not be linked to evident microstructural features. In contrast to the ammoniacal solution, the $\Delta \psi$ of the matrix decreased to $-715 \mathrm{mV}_{\mathrm{Ni}}$ by the end of the exposure, Table $\mathrm{V}$.

SEM-EDS analysis revealed the formation of chloride-rich deposits over the entire surface. The corrosion attack nucleated at the interface between both $\kappa_{\text {II }}$ and $\kappa_{\text {III }}$ phases and the $\alpha$-phase as shown in Figure 7, but no uniform dissolution of the matrix was observed. As with the results in the ammoniacal solution, EDS analysis sug-

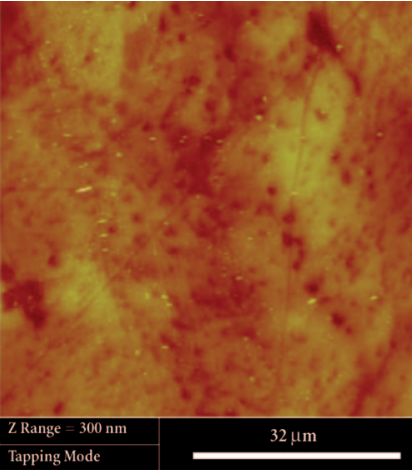

(a)

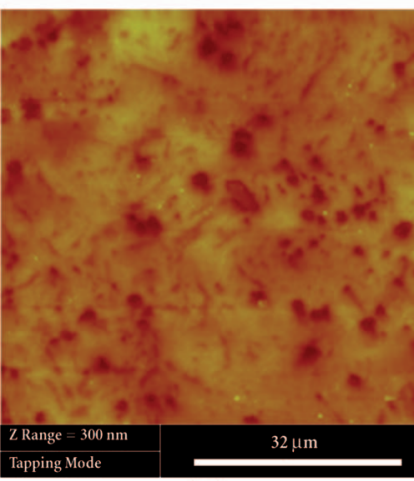

(c)

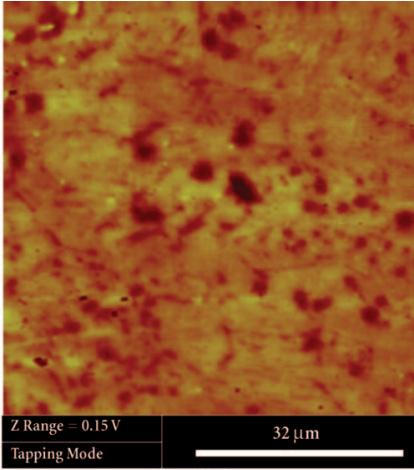

(b)

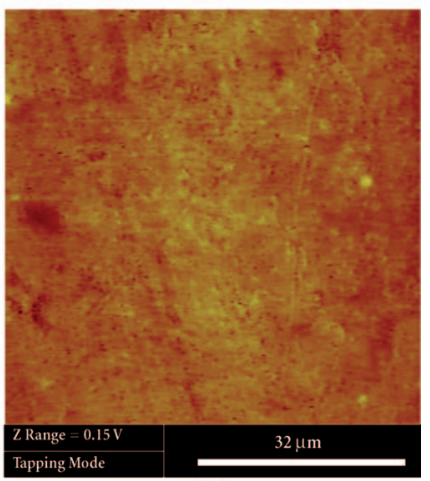

(d)
Figure 8. Topography (left) and Volta potential difference (right) evolution of as polished UNS C63200: (a) and (b) before exposure, (c) and (d) after a 30 min anodic polarization in $0.1 \mathrm{M} \mathrm{Na}_{2} \mathrm{SO}_{4}$ at and polarized potential of $70 \mathrm{mV}$ above $\mathrm{E}_{\text {Corr }}$, which resulted in a $\mathrm{I}=200 \mu \mathrm{A}$.

gested that IMCs remained free of attack, with the dissolution front advancing into the $\alpha$-phase, Figures $7 \mathrm{~b}$ and $7 \mathrm{c}$.

Potentiostatic exposure.-Anodic polarization.-Figure 8 shows both topography and Volta potential difference maps of another HT sample before and after anodic polarization at $70 \mathrm{mV}$ above the stable OCP value of $-250 \mathrm{mV}_{\mathrm{SCE}}$ in the chloride-free $\mathrm{Na}_{2} \mathrm{SO}_{4} \mathrm{pH} 5.3$ electrolyte. The sample was removed from the electrolyte under potential control and immediately analyzed by SKPFM. Guillaumin et al. showed that Volta potential difference maps measured a few minutes after emersion provided a faithful representation of the situation in solution. ${ }^{24}$ The topography plot after 30 minutes of exposure revealed no signs of localized corrosion, with only what could be the early stages of trenching at some $\kappa_{I I}-\alpha$ interfaces. This was later confirmed by optical microscopy (not shown.)

The anodic polarization resulted in a drastic change in Volta potential difference, Figure 8d. The contrast between IMCs and the matrix disappeared. Finely dispersed areas of high and low $\Delta \psi$ values were observed, which appeared randomly distributed over the surface with no apparent correlation with microstructure. Likewise, the absolute Volta potential of the $\alpha$ matrix decreased by approximately $80 \mathrm{mV}$, from approximately $-620 \mathrm{mV}_{\mathrm{Ni}}$ to $-700 \mathrm{mV}_{\mathrm{Ni}}$, Table $\mathrm{V}$.

The Volta potential contrast between the matrix and IMCs recovered after an overnight storage in a desiccator (image not shown).

Cathodic polarization.-Figure 9 shows the results of cathodic polarization at a potential $200 \mathrm{mV}$ below $\mathrm{OCP}$ in $\mathrm{Na}_{2} \mathrm{SO}_{4}$ at $\mathrm{pH} 5.3$. Surprisingly, this cathodic polarization led to localized corrosion, primarily at the $\kappa_{\mathrm{III}}-\alpha$ interface as seen in topography plots and visually confirmed by optical microscopy (not shown). In contrast with the results of the anodic polarization, no changes in Volta potential difference maps were observed after $30 \mathrm{~min}$ of cathodic polarization. All $\kappa$-phases displayed Volta potential difference values lower than the 


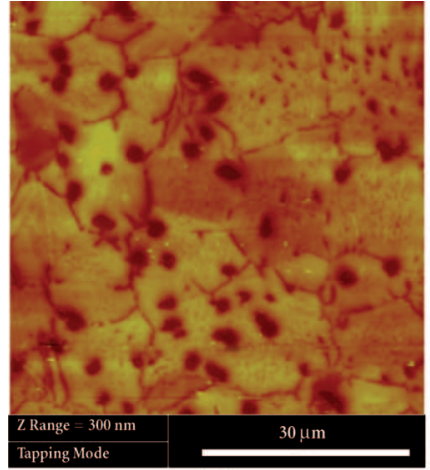

(a)

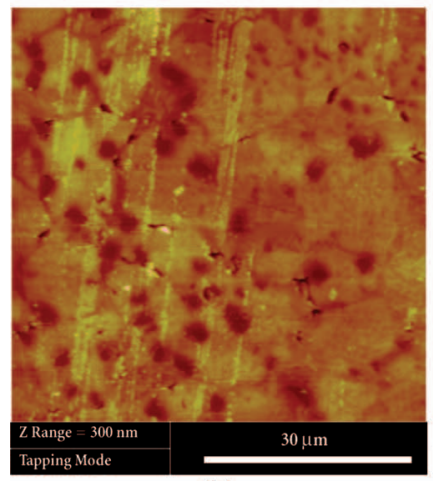

(b)

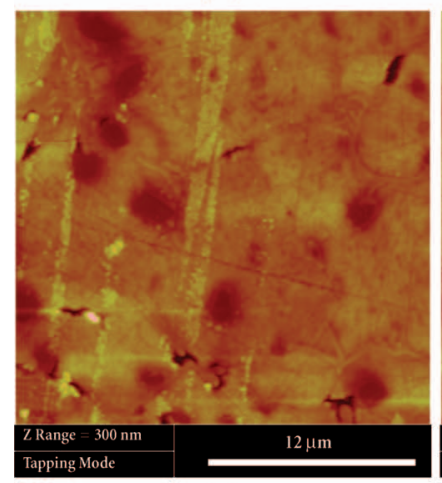

(e)

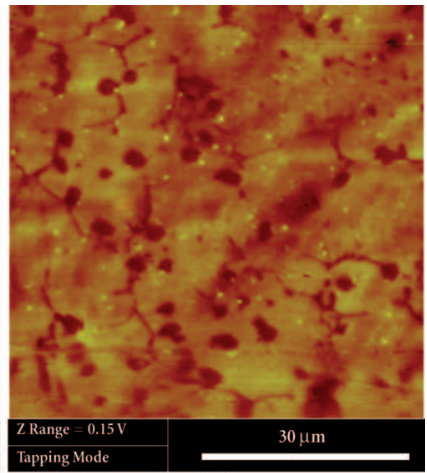

(b)

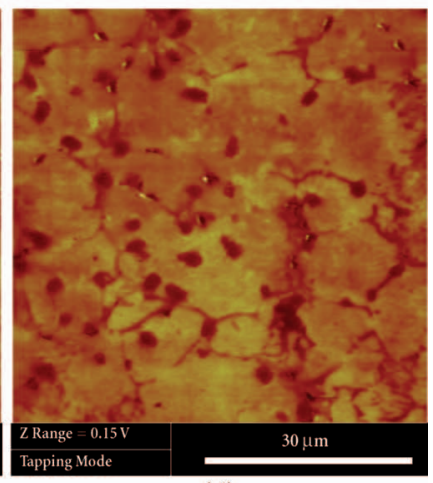

(d)

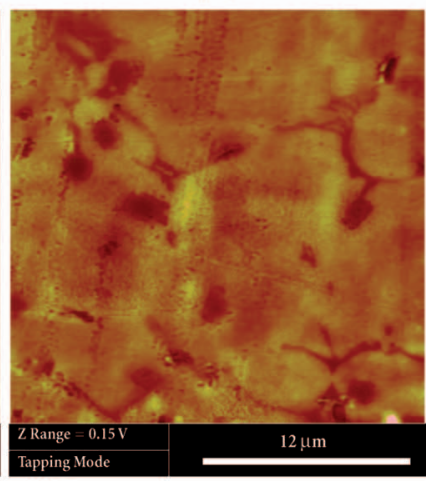

(f)
Figure 9. Topography (left) and Volta potential difference (right) evolution of as polished UNS C63200: (a) and (b) before exposure, (c) and (d), and (e) and (f) after a cathodic polarization in $0.1 \mathrm{M} \mathrm{Na}_{2} \mathrm{SO}_{4}$ at and polarized potential of $200 \mathrm{mV}$ below $\mathrm{E}_{\text {Corr }}$, which resulted in a $\mathrm{I}=-58 \mu \mathrm{A}$. (e) and (f) are higher magnification images showing clear signs of selective dissolution at some $\alpha-\kappa$ boundaries.

$\alpha$-matrix. The regions showing signs of selective dissolution in the form of trenching had the lowest Volta potential values. The mean absolute $\Delta \psi$ value of the $\alpha$-phase remained unchanged, with an average of $-625 \mathrm{mV}_{\mathrm{Ni}}$, Table $\mathrm{V}$.

\section{Discussion}

The findings of this investigation contradicted the welldocumented correlation between areas of low and high Volta potential difference and the expected anodic or cathodic behavior or practical nobility or reactivity. In particular, the $\alpha$-phase with the highest Volta potential difference exhibited selective dissolution, whereas the $\kappa$ phase IMCs were unattacked. However, the results were in accordance with the accepted corrosion mechanism of NABs in marine environments, in which the $\mathrm{Cu}$-rich $\alpha$-phase suffers selective dissolution when exposed to chloride-containing environments. The localization of the attack is driven by $\mathrm{Cu}$ oxidation, via $\mathrm{CuCl}^{-2}$ formation. ${ }^{9}$ In this mechanism, $\kappa$-phases serve as local cathodes and are protected by the formation of a self-protecting aluminum oxide layer. ${ }^{2,9,61}$ The presence of ammonia facilitates the corrosion of the $\alpha$-matrix by the formation of $\mathrm{Cu}\left(\mathrm{NH}_{3}\right)^{2+}$ and increases SCC susceptibility. ${ }^{20-22}$

Nakhaie and coworkers conducted an SKPFM study on a cast NAB. ${ }^{40}$ The alloy used by the researchers contained both $\kappa_{\mathrm{I}}$ and retained $\beta$ in addition to the other $\kappa$-phases, which is characteristic of cast microstructures. Like UNS C63200, all IMCs had a Volta potential difference lower than that of the $\alpha$-phase. The large $\kappa_{I}$ rosettes exhibited the lowest Volta potential values, with a maximum difference relative to the matrix of about $75 \mathrm{mV}$. The Volta potentials of $\kappa_{\text {II }}$ and $\kappa_{\text {III }}$ followed the same trend observed in this study. No clear contrast was found between the $\alpha$ and retained $\beta$ phases. Nakhaie et al. suggested that $\kappa_{\mathrm{I}}$ particles dissolved after a $30 \mathrm{~s}$ exposure to 0.1 $\mathrm{M} \mathrm{HCl}$ ( $\mathrm{pH}$ 1.0), as evidenced by SEM analysis. No signs of corrosion were seen on the other constituents. Thus, the authors concluded that the polarity obtained in Volta potential difference maps corresponded with the observed corrosion behavior.

More recently, Song et al. studied the nobility of the various phases present in an as-cast NAB and the same NAB subjected to a frictionstir processing (FSP). ${ }^{41}$ Samples were immersed in aerated acidic $(\mathrm{pH} 2.0)$ and neutral $3.5 \mathrm{wt} \% \mathrm{NaCl}$ solutions at room temperature. The investigators compared SKPFM maps obtained in the as-polished condition in air with the evolution of the corrosion attack as observed by SEM. Song et al. did not, however, conduct SKPFM measurements after exposure. Unlike the NAB studied in this investigation, the resulting microstructure of the as-cast and FSP NABs contained a large fraction of $\beta^{\prime}$ and $\kappa_{\mathrm{IV}}$-phase densely distributed within the $\alpha$-matrix. The FSP NAB had Widmanstätten $\alpha$ and fine $\beta$ ' phases as well as banded and equiaxed $\alpha$ and $\beta$,

It is worth noting that Song et al. did not invert the Volta potential map, which complicates the direct comparison of the results. The authors found selective dissolution of the $\kappa_{I I}$ and $\kappa_{I V}$ in the as-cast NAB exposed to the acidic chloride environment but no corrosion was observed on the $\alpha$-matrix. Selective attack was found on the lamellar $\kappa_{\text {III }}$-phase after $6 \mathrm{~h}$ of exposure. In contrast, corrosion initiated at the interface between $\kappa$-phases and the matrix in neutral $3.5 \mathrm{wt} \% \mathrm{NaCl}$. For the FSP NAB, corrosion of the small compounds present within $\beta$ ' took place during the initial 20 min of exposure to the acidic chloride solution with the subsequent dissolution of the $\beta$ ' phase. The authors concluded that the morphology observed in the $3.5 \mathrm{wt} \% \mathrm{NaCl}$ electrolyte at $\mathrm{pH} 2.0$ was consistent with SKPFM results. However, the results in the neutral chloride solution were contrary to the expected nobility of the $\alpha$-phase. The authors cautioned about possible misinterpretations when analyzing SKPFM results since the different phases could have either active or passive behaviors depending on the environment.

At a given chloride concentration, the corrosion behavior of NAB is strongly affected by $\mathrm{pH}$. Neodo et al. have shown that the $\alpha$-phase corroded preferentially in chloride-containing solutions above $\mathrm{pH} 4.0$, with $\kappa$ phase IMCs remaining free of attack and acting as local cathodes due to the formation of an $\mathrm{Al}_{2} \mathrm{O}_{3}$ layer. ${ }^{18}$ Krogstad and Johnsen recently reported a similar behavior on NABs when galvanically coupled to stainless steels and exposed to natural seawater. ${ }^{61}$ Selective corrosion attack, however, occurred on all $\kappa$ precipitates below $\mathrm{pH}$ 4.0 , leading to a reversal of the cathodic phase behavior in NAB. The reversal in corrosion behavior has also been reported inside crevice regions in a similar NAB by Wharton et al. ${ }^{17}$ The authors found that attack initiated at the $\alpha$ grains but propagated by $\kappa$-phase dissolution as the $\mathrm{pH}$ of the occluded region became more acidic. In this regard, $\kappa_{\text {III }}$ appeared to be especially susceptible. Similarly, Fonlupt et al. reported that SCC of NAB proceeded intergranularly at the $\alpha-\kappa$ interface, with the dissolution of the $\kappa$-phases within the crack environment playing a decisive role. ${ }^{19}$ The continuous lamellar $\kappa_{\mathrm{III}^{-}}$ phase was the most detrimental. ${ }^{19}$ While these findings support the observations of Nakhaie et al..$^{40}$ and Song et al., ${ }^{41}$ it is not possible to conclusively determine whether $\kappa$ particles selectively dissolved or if the attack started at the interface, leading to the undercutting suggested by Culpan and Rose $^{2}$ since the authors did not conduct AFM 


\begin{tabular}{|c|c|}
\hline Phase & Work Function, $\Phi(\mathrm{eV})$ \\
\hline$\alpha *$ & $4.595 \pm 0.002$ \\
\hline $\mathrm{\kappa}_{\mathrm{I}} *$ & $4.519 \pm 0.037$ \\
\hline$\kappa_{\mathrm{II}} *$ & $4.546 \pm 0.046$ \\
\hline $\mathrm{K}_{\mathrm{III}} *$ & $4.618 \pm 0.002$ \\
\hline $\mathrm{\kappa}_{\mathrm{IV}} *$ & $4.589 \pm 0.097$ \\
\hline$\alpha \ddagger$ & 4.607 \\
\hline$\kappa_{\text {III }} \ddagger$ & 4.598 \\
\hline$\kappa_{\text {II }}^{\ddagger}$ & 4.483 \\
\hline
\end{tabular}

at shorter incremental exposure intervals. Indeed, the morphology of the corrosion attack resembled the undercutting of Fe-containing IMCs in aluminum alloys seen during in situ AFM scratching. ${ }^{28,42}$ Likewise, the strong $\mathrm{pH}$ dependence of NAB corrosion could help explain the attack observed on cathodically polarized samples where the dissolution of the $\alpha$-matrix could occur due to local alkalization around IMCs.

Work functions.-While the observed corrosion morphology in both ammoniacal solutions and $0.5 \mathrm{M} \mathrm{NaCl}$ agreed with the documented behavior of NABs in chloride-containing solutions above $\mathrm{pH}$ 4.0, literature results did not explain the apparent contradiction with the corrosion behavior predicted from SKPFM. As can be seen in Table I and Table IV, $\kappa$-phases, particularly $\kappa_{\text {II }}$ and $\kappa_{\text {IV }}$, were enriched in $\mathrm{Al}$ and $\mathrm{Fe}$ and depleted in $\mathrm{Cu}$. In other words, $\kappa$-phases contained a larger fraction of elements with reversible potentials and work functions lower than $\mathrm{Cu} .{ }^{62,63}$ The partitioning of alloying elements in NABs contrasts with that in, e.g., aluminum alloys and stainless steels. In wrought aluminum alloys, precipitates that act as local cathodes are enriched in elements that are more noble than the Al-rich matrix and have a higher work function. ${ }^{23}$ Likewise, in stainless steels, the phases that promote a low pitting potential and serve as local anodes are impoverished in $\mathrm{Cr}$, Mo, and $\mathrm{W}^{64}$ and, hence, contain a lower fraction of elements with a high work function. For instance, Sathirachinda and colleagues found that the secondary austenite forming due to $\sigma$ phase precipitation had the lowest Volta potential in duplex stainless steels. ${ }^{47,51}$

Even though the work function of a compound cannot be calculated directly from the work functions of the individual constituents, representative trends can be obtained by ${ }^{65}$

$$
\phi=\sum_{i=1}^{n} x_{i} \cdot \phi_{i}
$$

where $\Phi$ is the work function of the compound, $x_{i}$ the atomic fractions and $\Phi_{i}$ the work functions of the elements that form the compound. Table VI summarizes the work function values of the $\alpha$-phase as well as all $\kappa$-phases estimated from the compositions shown in Table I and the EDS data presented in Table IV and considering $\Phi_{i}$ values reported in the literature. ${ }^{59}$ As seen in Table VI, using the compositions reported in the literature the $\kappa_{\mathrm{I}}, \kappa_{\mathrm{II}}$, and $\kappa_{\mathrm{IV}}$ precipitates had the lowest work functions and $\kappa_{\mathrm{II}}$ had the lowest work function using EDS results. The work function of the lamellar $\kappa_{\text {III }}$ phase varied widely as the composition shown in the literature had considerable dispersion. Using the composition reported by, e.g., Culpan and Rose, ${ }^{6} \kappa_{\text {III }}$ had the highest work function owing to its high Ni content. However, $\alpha$ had the highest work function value qualitatively calculated using Eq. 1 based on the composition obtained by EDS analysis on UNS C63200. Thus, for UNS C63200 the work functions varied, in decreasing order, from $\alpha>\kappa_{\text {III }}>\kappa_{\text {II }}\left(\kappa_{\text {IV }}\right)$.

The Volta potential values obtained in this investigation by SKPFM in air correlated well with the work functions of the compounds. However, the work function variation did not correspond with the observed corrosion behavior, which supports the observations of Rohwerder and Turcu as described above. ${ }^{36}$ In this regard, Rohwerder and Turcu highlighted that the corrosion response of a metal or alloy depends not only on composition and microstructure but also the environment, as illustrated by the corrosion behavior of NAB as a function of $\mathrm{pH}$. Thus, SKPFM in air might not reflect the complex interaction between the surface and the electrolyte and could lead to misinterpretations.

In this work, Volta potential difference maps after the early stages of corrosion at OCP or after a net cathodic polarization maintained the contrast observed in the as-polished condition despite the presence of corrosion reactions to the contrary. These results suggested that the Volta potential difference measured by SKPFM immediately after emersion is related to the work function of the compound but might not carry relevant information about the situation in solution, as previously found in aluminum alloys. ${ }^{24}$ Indeed, work functions are not only determined by metal ion constituents in the surface oxide, but also by factors such as fraction of hydroxide in the oxide and adsorption of other species. ${ }^{66,67}$ Although speculative, it is possible that the hydroxide content in the oxide could be affected by the different immersion conditions. It is, nonetheless, unclear why the Volta potential difference maps of anodically polarized samples showed no contrast between the matrix and the $\kappa$-phases, or why the absolute Volta potential of the matrix increased after OCP exposure to the ammoniacal solution but decreased after immersion in $\mathrm{NaCl}$. Future investigations should explore these inconsistencies further. Finally, with these limitations in mind, it seems reasonable to assume that Volta potential difference maps in air should not be universally correlated with practical nobility or reactivity.

\section{Conclusions}

The behavior of NAB contrasted with that of, e.g., aluminum alloys, which have been studied in detail by SKPFM. The reasons for the reverse correlation between Volta potential differences and corrosion morphology are not well understood, but the results support the conclusion of other researchers suggesting that SKPFM maps not always predict corrosion behavior. Considering these caveats, the following observations can be made:

- The Volta potential difference of the $\alpha$ matrix and the different $\kappa$-phases scaled, at least qualitatively, with the work function of the compounds. The $\alpha$-phase had the highest Volta potential difference, due to their high $\mathrm{Cu}$ content. In contrast, the presence of $\mathrm{Fe}$ and $\mathrm{Al}$ lowered the work function of $\kappa_{\text {II }}$ and $\kappa_{I V}$ particles, which corresponded well with observed Volta potential contrast. The work function of the lamellar $\kappa_{\text {III }}$ phase was higher than that of $\kappa_{\text {II }}$ and $\kappa_{\text {IV }}$, but lower, equal, or greater than the matrix, depending on the $\mathrm{Ni}$ and $\mathrm{Al}$ content.

- Selective dissolution of the $\mathrm{Cu}$-rich $\alpha$-phase was observed in both ammoniacal chloride solutions as well as in $0.5 \mathrm{M} \mathrm{NaCl}$. No signs of corrosion attack were seen on the $\kappa$-phases. These results agree with the well-documented behavior of NABs in chloride-containing environments with $\mathrm{pH}$ values above 4.0, but do not correspond with the practical nobility or reactivity a priori predicted by SKPFM.

- Whereas the contrast in the Volta potential maps of samples removed from the electrolyte under anodic potential control blurred, no changes were observed in the cathodically polarized specimens. Interestingly, corrosion at the interface between $\kappa$ and $\alpha$ phases was observed after cathodic polarization, which corresponded with a low Volta potential difference and might be caused by local alkalization.

- The SKPFM results on NAB strongly suggest that Volta potential difference maps in air should not be universally correlated with practical nobility or reactivity.

\section{Acknowledgments}

We thank the support of the Naval Surface Warfare CenterCarderock Division (NSWCCD). 


\section{References}

1. F. Hasan, A. Jahanafrooz, G. W. Lorimer, and N. Ridley, Metall Trans A, 13, 1337 (1982).

2. E. A. Culpan and G. Rose, British Corrosion Journal, 14, 160 (1979).

3. A. H. Tuthill, Mater Performance, 26, 12 (1987).

4. ISO 21457:2010, "Petroleum, petrochemical and natural gas industries - Materials selection and corrosion control for oil and gas production systems" (Geneva, Switzerland: International Organization for Standardization, 2010).

5. J. Anantapong, V. Uthaisangsuk, S. Suranuntchai, and A. Manonukul, Materials \& Design, 60, 233 (2014).

6. E. A. Culpan and G. Rose, Journal of Materials Science, 13, 1647 (1978).

7. P. Brezina, International Metals Reviews, 27, 77 (1982).

8. F. Hasan, J. Iqbal, and N. Ridley, Materials Science and Technology, 1, 312 (1986).

9. G. W. Lorimer, F. Hasan, J. Iqbal, and N. Ridley, British Corrosion Journal, 21, 244 (1986).

10. F. Hasan, G. W. Lorimer, and N. Ridley, Metal Science, 17, 289 (1983).

11. Z. Wu, Y. F. Cheng, L. Liu, W. Lv, and W. Hu, Corros Sci, 98, 260 (2015).

12. A. Jahanafrooz, F. Hasan, G. W. Lorimer, and N. Ridley, Metall Trans A, 14, 1951 (1983).

13. A. Schüssler and H. E. Exner, Corros Sci, 34, 1793 (1993).

14. A. Schüssler and H. E. Exner, Corros Sci, 34, 1803 (1993).

15. J. A. Wharton, R. C. Barik, G. Kear, R. J. K. Wood, K. R. Stokes, and F. C. Walsh, Corros Sci, 47, 3336 (2005).

16. J. A. Wharton and K. R. Stokes, Electrochemistry Communications, 9, 1035 (2007).

17. J. A. Wharton and K. R. Stokes, Electrochim Acta, 53, 2463 (2008).

18. S. Neodo, D. Carugo, J. A. Wharton, and K. R. Stokes, J Electroanal Chem, 695, 38 (2013).

19. S. Fonlupt, B. Bayle, D. Delafosse, and J.-L. Heuze, Corros Sci, 47, 2792 (2005).

20. K. L. Vasanth and R. Hays, Corrosion Assessment of Nickel Aluminum Bronze (NAB in Seawater, in CORROSION 2004, NACE International, New Orleans, LA (2004).

21. T. P. Hoar and G. P. Rothwell, Electrochim Acta, 15, 1037 (1970).

22. D. C. Agarwal, Journal of Failure Analysis and Prevention, 3, 58 (2003)

23. P. Schmutz and G. S. Frankel, J. Electrochem. Soc., 145, 2285 (1998).

24. V. Guillaumin, P. Schmutz, and G. S. Frankel, J. Electrochem. Soc., 148, B163 (2001).

25. P. Schmutz and G. S. Frankel, J. Electrochem. Soc., 145, 2295 (1998).

26. S. Yee, R. A. Oriani, and M. Stratmann, J. Electrochem. Soc., 138, 55 (1991).

27. A. B. Cook, Z. Barrett, S. B. Lyon, H. N. McMurray, J. Walton, and G. Williams, Electrochim Acta, 66, 100 (2012).

28. P. Leblanc and G. S. Frankel, J. Electrochem. Soc., 149, B239 (2002).

29. R. G. Buchheit, R. P. Grant, P. F. Hlava, B. Mckenzie, and G. L. Zender, J. Electrochem. Soc., 144, 2621 (1997).

30. L. Lacroix, L. Ressier, C. Blanc, and G. Mankowski, J. Electrochem. Soc., 155, C8 (2008).

31. R. G. Buchheit, J. Electrochem. Soc., 142, 3994 (1995).

32. R. G. Buchheit, L. P. Montes, M. A. Martinez, J. Michael, and P. F. Hlava, J. Electrochem. Soc., 146, 4424 (1999).
33. W. R. McGovern, P. Schmutz, R. G. Buchheit, and R. L. McCreery, J. Electrochem. Soc., 147, 4494 (2000).

34. N. Birbilis and R. G. Buchheit, J. Electrochem. Soc., 152, B140 (2005).

35. P. Schmutz and G. S. Frankel, J. Electrochem. Soc., 146, 4461 (1999).

36. M. Rohwerder and F. Turcu, Electrochim Acta, 53, 290 (2007).

37. M. Pourbaix, Corros Sci, 35, 1167 (1993).

38. E. Asselin, T. M. Ahmed, and A. Alfantazi, Corros Sci, 49, 694 (2007).

39. T. H. Muster and A. E. Hughes, J. Electrochem. Soc., 153, B474 (2006)

40. D. Nakhaie, A. Davoodi, and A. Imani, Corros Sci, 80, 104 (2014).

41. Q. N. Song, Y. G. Zheng, D. R. Ni, and Z. Y. Ma, Corros Sci, 92, 95 (2015).

42. M. Iannuzzi and G. S. Frankel, Corrosion, 63, 672 (2007).

43. O. Lopez-Garrity and G. S. Frankel, Corrosion, 70, 928 (2014).

44. S. Pawar, X. Zhou, G. E. Thompson, G. Scamans, and Z. Fan, J. Electrochem. Soc., 162, C442 (2015)

45. K. Kondoh, N. Nakanishi, R. Takei, H. Fukuda, and J. Umeda, Light Metals Technology $V, \mathbf{6 9 0}, 397$ (2011).

46. M. Jönsson, D. Thierry, and N. LeBozec, Corros Sci, 48, 1193 (2006).

47. N. Sathirachinda, R. Pettersson, and J. Pan, Corros Sci, 51, 1850 (2009).

48. N. Sathirachinda, R. Pettersson, S. Wessman, and J. Pan, Corros Sci, 52, 179 (2010).

49. C. Örnek, J. Walton, T. Hashimoto, T. L. Ladwein, S. B. Lyon, and D. L. Engelberg, J. Electrochem. Soc., 164, C207 (2017).

50. H. Yanliang, B. Kinsella, and T. Becker, Mater Lett, 62, 1863 (2008).

51. N. Sathirachinda, R. Gubner, J. Pan, and U. Kivisäkk, Electrochemical and Solid-State Letters, 11, C41 (2008).

52. R. I. Revilla, J. Liang, S. Godet, and Graeve, J. Electrochem. Soc., 164, C27 (2017).

53. S. Rahman, G. Priyadarshan, K. S. Raja, C. Nesbitt, and M. Misra, Mater Lett, 62, 2263 (2008).

54. P. P. Bai, H. Zhao, S. Q. Zheng, and C. F. Chen, Corros Sci, 93, 109 (2015).

55. A. Fedrizzi, M. Pellizzari, M. Zadra, and E. Marin, Mater Charact, 86, 69 (2013).

56. P. P. Leblanc and G. S. Frankel, J. Electrochem. Soc., 151, B105 (2004).

57. C. Senöz, S. Borodin, M. Stratmann, and M. Rohwerder, Corros Sci, 58, 307 (2012).

58. C. Senöz and M. Rohwerder, Electrochim Acta, 56, 9588 (2011).

59. S. Halas and T. Durakiewicz, J Phys-Condens Mat, 10, 10815 (1998)

60. ASTM B171/B171M-12, "Standard Specification for Copper-Alloy Plate and Sheet for Pressure Vessels, Condensers, and Heat Exchangers" (West Conshohocken, PA: ASTM International, 2012).

61. H. N. Krogstad and R. Johnsen, Corros Sci, (2017).

62. H. B. Michaelson, Journal of Applied Physics, 48, 4729 (1977).

63. D. A. Jones, in Principles and Prevention of Corrosion, 2nd ed., p. 44, Prentice Hall, Upper Saddle River, NJ (1996).

64. A. J. Sedriks, Corrosion, 45, 510 (1989)

65. J. A. Rothschild and M. Eizenberg, Physical Review B, 81, (2010).

66. Ö. Özkanat, B. Salgin, M. Rohwerder, J. M. C. Mol, J. H. W. de Wit, and H. Terryn, The Journal of Physical Chemistry C, 116, 1805 (2012).

67. R. Hausbrand, M. Stratmann, and M. Rohwerder, J. Electrochem. Soc., 155, C369 (2008). 